Research Journal of Biological Sciences 14 (3-6): 56-60, 2019

ISSN: 1815-8846

(C) Medwell Journals, 2019

\title{
Hypoglycemic, Hypolipidimic and Protective Effects of Arbutus andrachne Extract in Streptozotocin Induced Diabetic Rats
}

\author{
${ }^{1}$ Ahmed Abu-Zaiton, ${ }^{2}$ Mahmoud Abu-Samak, ${ }^{3}$ Sawsan Oran, ${ }^{3}$ Israa Yousef, \\ ${ }^{4}$ Yousef Abu-Zaitoon and ${ }^{5}$ Ayah Algaramseh \\ ${ }^{1}$ Department of Biology, Al-Albayt University, Al-Mafraq, Jordan \\ ${ }^{2}$ Faculty of Pharmacy, Applied Science University, Al Eker, Bahrain \\ ${ }^{3}$ Department of Biology, The University of Jordan, Amman, Jordan \\ ${ }^{4}$ Department of Biology, Al-Hussein Talal University, Meian, Jordan \\ ${ }^{5}$ Departmrnt of Biology, Mutah University, Mutah, Joradn
}

\begin{abstract}
The aim of this study is to investigate the anti-hyperglycemic effect, lipid profile and the activity of certain hepatic enzymes of the ethanolic extract of the plant Arbutus andrachne on streptozotocin-induced diabetic rats. About 30 Wistar albino rats weighing between 180-200 g were randomly classified into four categories of six albino rats. The normal control group (group A) was treated orally with distilled water. The diabetic control group (group B) was induced by streptozotocin. So, this group is considered as a negative control. The non diabetic rats (group C) which was treated with the ethanolic extract of the plant A. andrachne that collected from Jerash/Jordan of a dose $200 \mathrm{mg} \mathrm{kg}^{-1}$. The last group (Group D) which included the diabetic rats that treated with $200 \mathrm{mg} \mathrm{kg}^{-1}$ of the ethanoilc extract of the plant A. andrachne. The treatment was carried out daily for 14 days. The glucose, triglycerides, cholesterol and hepatic enzymes levels were quantified in serum of experimental rats. Study was carried out in Faculty of Pharmacy/Applied Science University (December, 2018) and Botany Lab, Department of Biological sciences/University of Jordan. The results unambiguously showed that there was significant declines $(\mathrm{p}<0.05)$ in triglycerides and glucose levels in albino rats that treated with A. andrachne ethanolic extract compared with group B, the control group of diabetic rats. Significant reduction $(\mathrm{p}<0.05)$ in hepatic enzymes -AST and ALT-levels were also observed in rats treated with the plant ethanoilc extract compared with group B experimental rats. However, no significant changes in the cholesterol level were observed in the treated rats compared with the control group. Data in this piece of research revealed that the plant A. andrachne ethanolic extract has both hypoglycemic and hypolipidimic effect. This extract is suggested to reduce the liver damage induced by streptozotocin through maintaining the activity of hepatic enzymes.
\end{abstract}

$\underline{\text { Key words: Anti-diabetic, A. andrachne, liver enzymes, streptozotocin, hypoglycemic agent, medicinal plants }}$

\section{INTRODUCTION}

Diabetes mellitus is a chronic disease occurs due to either an autoimmune disorder or insulin resistance. Autoimmune disorder (type I diabetes) appears as a result of $\beta$-cells failure to secrete insulin (Aja et al., 2015). Interrupted signal transduction pathway occurs as a result of defects of insulin receptors which is routinely called type II diabetes leading to elevated blood glucose level (hyperglycemia) (Bamidele et al., 2014). One possible line of hyperglycemic treatment can be performed by intensive use of insulin. However, in certain cases this strategy may be ineffective to reduce glucose level and as a result hypoglycemic intervention should be implemented. In this research, A. andrachne ethanolic extract is investigated to detect whether it has hypoglycemic effects on rats or not. Diabetes is associated with a wide group of abnormalities including dyslipidemia, increased transcript of inflammatory biomarkers, changes in normal levels of hepatic enzymes and hemodynamic changes (WHO., 1985).

The dyslipidemia that linked to type II diabetes and insulin resistance can be recognized by increased triglycerides as well as decreased cholesterol level. Discrepancy in levels of triglycerides and cholesterol is highly risky for cardiovascular system (Baumgartner et al., 2011). Several plant species were reported to reduce levels of lipids in diabetes as a way to reduce severe symptoms of this disease. In this research, the probability of hypolipidimic effect of $A$. andrachne extract is investigated.

Different techniques were implemented to induce diabetes experimentally one of the most efficiently technique is to use the chemical Streptozotocin

Corresponding Author: Ahmed Abu-Zaiton, Department of Biology, Al-Albayt University, Al-Mafraq, Jordan 
(STZ). Streptozotocin enters pancreatic $\beta$-cells by GLUT2 receptors which then modify DNA through, alkylation which therefore, causes activation of poly ADP-ribosylation. Furthermore, streptozotocin produces harmful quantities of Nitric Oxides which down regulates aconitase activity. Streptozotocin participates in pancreatic $\beta$-cells destructions through necrosis (Szkudelski, 2001).

Treatment with medicinal plants comparing to synthetic drugs is characterized by low cost, less toxicity and undesirable side effects or contraindications (Dieye et al., 2008). Management of diabetes through using a wide variety of plant extracts has been highly recommended in the recent few years. One of these suggested plants is A. andrachne L. which has edible fruits and belongs to the family Ericaceae that includes about 50 genera and more than 1350 species. South Asia and Mediterranean are their native (Bacic et al., 1992). A. andrachne is distributed in different parts of Jordan, mainly in the north areas. It is found as a shrub or tree growing up to $5 \mathrm{~m}$. The leaves of $A$. andrachne are elliptic and glabrous. March to April is the time for flowering while the fruits time is from October to November. The different parts of $A$. andrachne have used for treatment of disorders of urinary tract (Bamidele et al., 2014). The fruits and roots of $A$. andrachne have been used for allaying joints pain and wound healing (Serce et al., 2010). Glycosides, terpenoids and phenolic compounds are active ingredients that isolated from the ethanolic extract of $A$. andrachne stem (Bacic et al., 1992). Arbutus fruit extract may prevent chronic SD-induced impairment of hippocampal memory by its antioxidative potential (Alzoubi et al., 2018). Even though A. andrachne has been widely accepted as an important medicinal plant for treating a wide range of diseases, its effects on diabetes have not been reported. Therefore, this research is investigated the effects of this popular plant in Jordan-on various aspects of diabetes for the first time.

In this study, however was attempting to explore the biochemical effect of $A$. andrachne extract on blood glucose, lipid profile and liver enzymes levels. So, the present study is performed to study the proposed mechanism beyond anti hyperglycemic and hypolipidimic influences of $A$. andrachne on streptozotocin induced diabetic rats.

\section{MATERIALS AND METHODS}

Plant materials: The leaves of the plant $A$. andrachne were collected by Sawsan Oran from Jeresh/Jordan during Summer 2018 and completely dried. The plant has been taxonomically identified by Professor Sawsan Oran, plant taxonomy (Department of Biological Sciences, The University of Jordan). Voucher specimens of collected plants were deposited at Jordan University herbarium.
Preparation of plant extract: Collected leaves of A. andrachne were air dried for approximately 4 weeks at room temperature $\left(23-27^{\circ} \mathrm{C}\right)$. Dried plant materials were powdered using an electrical blender. About $60 \mathrm{~g}$ of each dried powdered plant material was dissolved separately in $600 \mathrm{~mL}$ of absolute ethanol (solvent to sample ratio of $(10: 1 \mathrm{v} / \mathrm{w})$ solvent to dry weight ratio) by using a reflux for $72 \mathrm{~h}$ with $60^{\circ} \mathrm{C}$. The extraction was then filtered through Whitman No. 1 filter papers. The filtrates were concentrated (evaporated of solvents) by using rotary evaporator with $40^{\circ} \mathrm{C}$ and subsequently left to completely dry (Serce et al., 2010).

Experimental design: Thirty Wistar albino rats weighing between 180-200 g were obtained from the animal house of the Faculty of Pharmacy, Applied Science University. The rats were divided into four groups of six rats. Each group was kept on different cages. The grouping was done as follows:

- $\quad$ Group A, control (non-diabetic rats)

- Group B, diabetic rats were induced with streptozotocin (negative control)

- Group C, non diabetic rats treated with A. andrachne extract at a dose of $200 \mathrm{mg} \mathrm{kg}^{-1}$

- Group D, diabetic rat's intubation with A. andrachne extract. The administration was done twice daily for 14 days

Induction of diabetes mellitus: Streptozotocin was dissolved in citrate buffer ( $\mathrm{pH} 4.5$ ) to induce diabetes in rats of groups $\mathrm{C}$ and $\mathrm{D}$ by intra-peritoneal injection at dose $60 \mathrm{mg} \mathrm{kg}^{-1}$ of body weight using insulin syringes. Diabetes induction was occurred after 3 days confirmed by testing the fasting blood glucose level using glucometer (Rees and Alcolado, 2005) also the symptoms of polyuria, polydipsia and glycosuria in diabetic rats was observed. Animals with blood sugar level more than $200 \mathrm{mg} \mathrm{dL}^{-1}$ were considered to be diabetic (Cerieello and Motz, 2004).

Blood collection and preparation: At the end of experiment, blood samples were collected by cervical dislocation of rats under chloroform anesthesia and drain into heparinized tubes and transferred into plain centrifuge tubes. They were then centrifuged within $1 \mathrm{~h}$ of collection at $4000 \times \mathrm{g}$ for $10 \mathrm{~min}$ on a centrifuge to separate the sera from the clot (Ochei and Kolhatkar, 2007).

Determination of blood glucose level: Blood glucose level was determined by the Glucose Oxidase Method (GOM) using reactive strips and a single touch glucometer. 
Serum lipids profile estimation: Enzymatic colorimetric method was used to measure the serum total cholesterol and triglycerides levels using Mannheim diagnostic kits.

Determination of liver enzymes: Aspartate Aminotransferase (AST) and Alanine Aminotransferase (ALT) were measured using commercial kits (Ochei and Kolhatkar, 2007).

Data analysis: All the values were shown as mean standard deviation. One-way Analysis of Variance (ANOVA) was used to studying and analyzing the data followed by post-hoc tests. The results are considered significant at $\mathrm{p}<0.05$.

\section{RESULTS AND DISCUSSION}

Table 1 shows body weight of control and diabetic rats with and without treatment with $A$. andrachne extract. After 14 days of experiment, there was a significant decrease $(\mathrm{p}<0.05)$ in the diabetic rats group (II) body weight compared with the control (group I). Administration of $A$. andrachne extract with diabetic experimental animals (group IV) has increased body weight significantly, comparing with the normal rats body weight.

Treating experimental rats with streptozotocin increased blood glucose level by more than four folds (Fig. 1). When diabetic albino rats were treated with A.andrachne extract, glucose level decreased significantly $(\mathrm{p}<0.05)$. After this treatment, glucose level returned to almost the normal level before streptozotocin treatment. A. andrachne extract cured diabetic rats completely.

Comparing to the control rats group, triglycerides level increased significantly $(p<0.05)$ in the STZ-treated diabetic rats group. However, no significant change was observed for cholesterol (Fig. 2). When STZ-diabetic rats were treated with the $A$. andrachne extract, a significant reduction was observed $(p<0.05)$ in the serum level of triglycerides whereas no significant changes in the level of cholesterol was observed.

Changes in the level of hepatic enzymes including Aspartate aminotransferase and Alanine aminotransferase were also investigated in this study. Figure 3 clearly shows a significant reduction $(\mathrm{p}<0.05)$ in the level of AST and ALT enzymes after treating albino rats with A. andrachne ethanolic extract comparing to the experimental animals in the control group.

Nowadays, using synthetic drugs to decrease serum glucose and lipid level in diabetic patients with hyperlipidemia and hyperglycemia is relatively reduced because of their side effects and using medicinal plant extracts has been increased (Baumgartner et al., 2011).

The current research was initially designed to explore the effect of $A$. andrachne ethanoilc extract on body weight of streptozotocin-induced diabetic albino rats. Additionally, levels of glucose, triglycerides and
Table 1: Effect of Arbutus rachne extract on the body weight of control and experimental animals

\begin{tabular}{lllc}
\hline & & \multicolumn{2}{l}{ Body weight } \\
\cline { 3 - 4 } Groups & Variables & Initial & Final \\
\hline I & Control & $190.2 \pm 16.6$ & $210.5 \pm 15.2$ \\
II & Diabetic & $195.5 \pm 12.7$ & $165.3 \pm 16.3^{\mathrm{a}}$ \\
III & Arbutus andrachne & $191.3 \pm 17.5$ & $194.1 \pm 13.4^{\mathrm{b}}$ \\
IV & Diabetic + A. andrachne & $194.2 \pm 16.7$ & $196.8 \pm 4.40$ \\
\hline All data are presented as Mean \pm SD & &
\end{tabular}

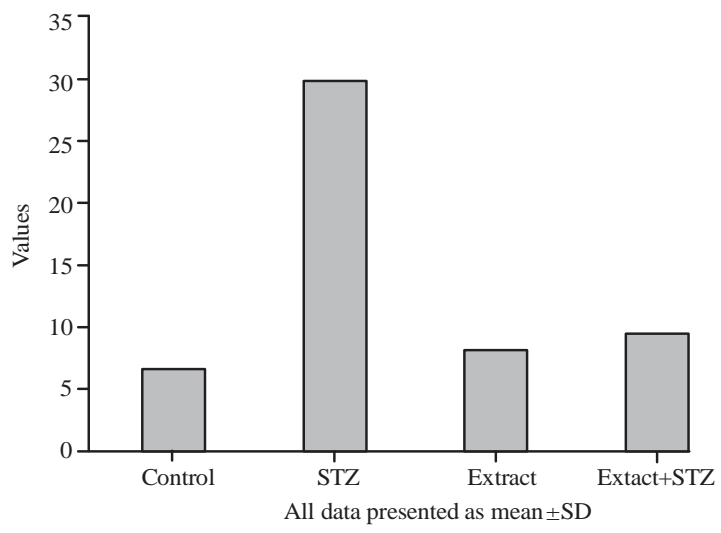

Fig. 1:Effect of Arbutus andrachne extract on glucose level in normal and diabetic rats

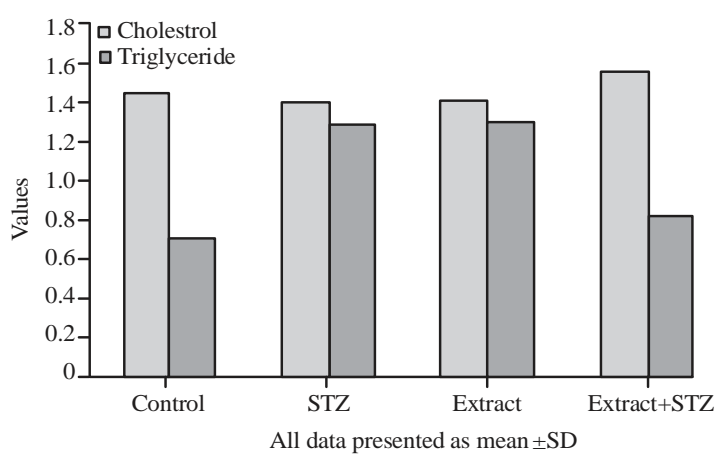

Fig. 2: Effect of Arbutus andrachne extract on cholesterol and triglycerides in normal and diabetic rats

cholesterol as well as aspartate amino transferase and alanine amino transferase liver enzymes were also investigated in the diabetic animals.

Firstly, body weight of streptozotocin-induced albino rats has been found to be significantly decreased at the end of the experimental work. In contrast, A. andrachne ethanoilc extract helps rat bodies to completely avoid weight reduction.

The decreasing in the body weight of diabetic rats is in agreement with the results by Oyedemi et al. (2011) who found the same effect of streptozotocin on diabetic animals by destruction of muscle protein which leading to 


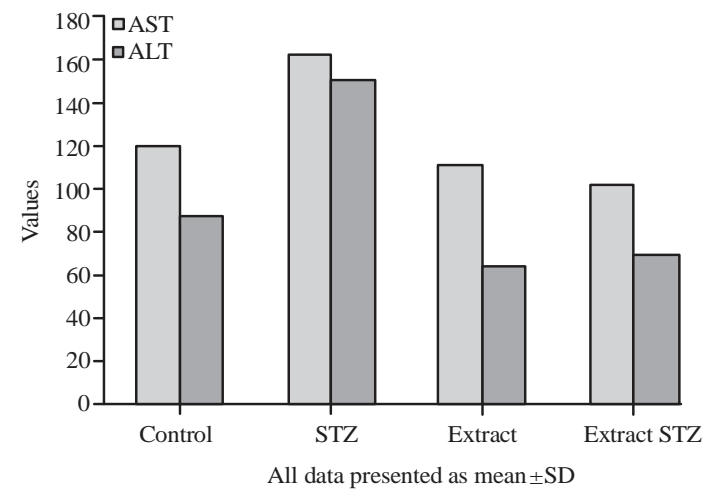

Fig. 3: Levels of liver enzymes in streptozotocin-induced diabetic albino rats after treatment with Arbutus andrachne extract.

lose weight but the oral administration of $A$. andrachne ethanoilc extract was normalizing body weight of the animals which may be due to the ability of the treatment to elevate blood glucose level as well as maintain muscle wasting.

On the other hand, this study is also investigated the antihyperlipidemic effect of $A$. andrachne ethanoilc extract in streptozotocin induced diabetic rats. The elevation of the triglycerides in streptozotocin-induced diabetic rats is due to the activity of mobilization of free fatty acids from the adipose tissues and the decrease of the insulin uptake and metabolism (Abu-Zaiton, 2019). According to the data that obtained from this study, A. andrachne ethanoilc extract has been found to have both hypoglycemic and hypolipidimic effects on streptozotocin-induced diabetic Wistar albino rats. In addition, according to the different phytochemicals that found in A. andrachne, A. andrachne has reduced the liver damage and normalizing the hepatic enzymes AST and ALT that happened because of streptozotocin induction (Issa et al., 2008). A. andrachne could improve glucose utilization in animal tissues, leading to prevent lipid peroxidation and regulate of lipolytic hormones. There are different plants that have reported to have anti-hyperlipidemic efficiency in such a manner. Many researchers have reported that active ingredients which isolated from plants extracts have induce a significant anti-hyperlipidemic effects due to their abilities to prevent of the cholesterol absorption and activate excretion by bile (Akpan et al., 2012).

On the other side, the significant decrease in the level of glucose of streptozotocin-induced diabetic animals may be arise as a result of inhibiting glucose absorption by one or more of the effective compounds of A. andrachne ethanoilc extract and the regenerating of pancreatic cells could be a possible for the antihyperglycemic potential activity of the A. andrachne ethanoilc extract. The possibility of regulating activity or expression of enzymes involved in the metabolic pathways of the examined compounds is not excluded (Kyung et al., 2006). It will be interesting to analyze the components of the ethanoilc extract and identifying the active compounds. However, more investigations are needed for evaluation the potential activity of $A$. andrachne and its extact traditional usage in diabetes treatment. Further studies for phytochemicals and toxicological information of $A$. andrachne should be study before administration and treatment with its extracts which will increase the efficiency of coming research.

\section{CONCLUSION}

The results of the present study demonstrate that the ethanolic extract of $A$. andrachne has hypoglycemic and hypolipidimic effects. In addition, A. andrachne has a protective effect on the hepatic enzymes and this will decrease the probability of liver damaged by streptozotocin.

\section{ACKNOWLEDGEMENTS}

The researchers are appreciating the support of Al-Albayt University and the University of Jordan, Botany Lab/Biology Department many thank to Dr. Abu-Samak for using his research lab and animal house unit in Applied Science University, Amman.

\section{REFERENCES}

Abu-Zaiton, A.S., 2019. Hypolipidemic and antioxidant effect of essential oil of Varthemia iphionoides in streptozotocin-induced diabetic rats. J. Chem. Pharm. Sci., 12: 51-54.

Aja, P.M., O.G. Ani, C.E. Offor, U.O. Orji and E.U. Alum, 2015. Evaluation of anti-diabetic effect and liver enzymes activity of ethanol extract of Pterocarpus santalinoides in alloxan induced diabetic albino rats. Global J. Biotechnol. Biochem., 10: 77-83.

Akpan, E.J., J.E. Okokon and E. Offong, 2012. Antidiabetic and hypolipidemic activities of ethanolic leaf extract and fractions of Melanthera scandens. Asian Pac. J. Trop. Biomed., 2: 523-527.

Alzoubi, K.H., B.S. Malkawi, O.F. Khabour, T. El-Elimat and F.Q. Alali, 2018. Arbutus andrachne L. reverses sleep deprivation-induced memory impairments in rats. Mol. Neurobiol., 55: 1150-1156.

Bacic, T., T.J. Lawrence and D.F. Cutler, 1992. Leaf anatomy of an Arbutus taxon from Yugoslavia. Kew Bull., 47: 535-543. 
Bamidele, O., D.S. Arokoyo, A.M. Akinnuga and A.O. Oluwarole, 2014. Antidiabetic effect of aqueous extract of Basella alba leaves and metformin in alloxan-induced diabetic albino rats. Afr. J. Biotechnol., 13: 2455-2458.

Baumgartner, S., R.P. Mensink and J. Plat, 2011. Plant sterols and stanols in the treatment of dyslipidemia: New insights into targets and mechanisms related to cardiovascular risk. Curr. Pharm. Des., 17: 922-932.

Ceriello, A. and E. Motz, 2004. Is oxidative stress the pathogenic mechanism underlying insulin resistance, diabetes and cardiovascular disease? The common soil hypothesis revisited. Arteriosclerosis Thrombosis Vasc. Biol., 24: 816-823.

Dieye, A.M., A. Sarr, S.N. Diop, M. Ndiaye and G.Y. Sy et al., 2008. Medicinal plants and the treatment of diabetes in Senegal: Survey with patients. Fundam. Clin. Pharmacol., 22: 211-216.

Issa, R.A., F.U. Afifi and B.I. Amro, 2008. Studying the anti-tyrosinase effect of Arbutus andrachne $\mathrm{L}$. extracts. Int. J. Cosmet. Sci., 30: 271-276.
Kyung, K.H., K.M. Jeong, C.H. Yon, K. Eun-Ki and S.D. Hoon, 2006. Antioxidative and anti-diabetic effects of amaranth (Amaranthus esculantus) in streptozotocin-induced diabetic rats. Cell Biochem. Funct., 24: 195-199.

Ochei, J. and A. Kolhatkar, 2007. Medical Laboratory Science: Theory and Practice. 6th Edn., Tata McGraw Hill, New Delhi, India, Pages: 158.

Oyedemi, S.O., E.A. Adewusi, O.A. Aiyegoro and D.A. Akinpelu, 2011. Antidiabetic and haematological effect of aqueous extract of stem bark of Afzelia africana (Smith) on streptozotocin-induced diabetic Wistar rats. Asian Pacific J. Trop. Biomed., 1: 353-358.

Rees, D.A. and J.C. Alcolado, 2005. Animal models of diabetes mellitus. Diabet. Med., 22: 359-370.

Serce, S., M. Ozgen, A.A. Torun and S. Ercisli, 2010. Chemical composition, antioxidant activities and total phenolic content of Arbutus andrachne L. (Fam. Ericaceae) (the Greek strawberry tree) fruits from Turkey. J. Food Comp. Anal., 23: 619-623.

Szkudelski, T., 2001. The mechanism of alloxan and streptozotocin action in B cells of the rat pancreas. Physiol. Res., 50: 537-546.

WHO., 1985. Diabetes mellitus: Report of a WHO study group (No. 727). World Health Organization, Geneva, Switzerland. 